\title{
The Need for Training of Computer and Information Systems Managers
}

\author{
Sonja Treven \\ University of Maribor, Maribor, Slovenia \\ sonja.treven@uni-mb.si
}

\begin{abstract}
In the paper the author first presents the nature of work that is characteristic for computer and information systems managers. Then she turns her attention to the increasing need for those profile of personnel. The requirements for training and other qualifications of computer and information systems managers are discussed widely as well. In the end the author presents the activity of training and various methods that can be applied in the training process.
\end{abstract}

Keywords: information system, managers, training, methods, work

\section{Introduction}

The need for organizations to incorporate existing and future technologies in order to remain competitive has become a more pressing issue over the last several years. As electronic commerce becomes more common, how and when companies use technology are critical issues.

Computer and information systems managers play a vital role in the technological direction of their organizations. They do everything from constructing the business plan to overseeing network and Internet operations. Hence, they have been fully acquainted with the strategic management of their companies as well as with their technology resources.

In the paper we shall emanate from the nature of work that is characteristic for computer and information systems managers. Then we shall turn our attention to the increasing need for the profile of personnel. The requirements for training and other qualifications of computer and information systems managers will be discussed widely as well. In the end we shall present the activity of training and various methods that can be applied in the training process.

\section{The Assignments of Information Systems Managers}

In this section we shall discuss what computer and information systems managers do. They perform some or all of the following duties:

- Plan, organize, direct, control and evaluate the operations of information systems and

Material published as part of these proceedings, either on-line or in print, is copyrighted by Informing Science. Permission to make digital or paper copy of part or all of these works for personal or classroom use is granted without fee provided that the copies are not made or distributed for profit or commercial advantage AND that copies 1) bear this notice in full and 2) give the full citation on the first page. It is permissible to abstract these works so long as credit is given. To copy in all other cases or to republish or to post on a server or to redistribute to lists requires specific permission from the publisher at Publisher@InformingScience.org electronic data processing (EDP) departments and companies.

- Develop and implement policies and procedures for electronic data processing and computer systems operations 
and development.

- Meet with clients to discuss system requirements, specifications, costs and timelines.

- Assemble and manage teams of information systems personnel to design, develop, implement, operate and administer computer and telecommunications software, networks and information systems.

- Control the budget and expenditures of the department, company or project.

- Recruit and supervise computer analysts, engineers, programmers, technicians and other personnel and oversee their professional development and training.

Broader description of the assignments of the computer and information systems managers is as follows. These managers plan, coordinate, and direct research and design the computer-related activities of firms. They determine technical goals in consultation with top management, and make detailed plans for the accomplishment of these goals. For example, working with their staff, they may develop the overall concepts of a new product or identify computer-related problems standing in the way of project completion (Veljovic, 2002).

Computer and information systems managers direct the work of systems analysts, computer programmers, support specialists, and other computer-related workers. These managers plan and coordinate activities such as the installation and upgrading of hardware and software, programming and systems design, the development of computer networks, and the implementation of Internet and intranet sites. They are increasingly involved with the upkeep and maintenance of networks. They analyze the computer and information needs of their organization and determine personnel and equipment requirements. They assign and review the work of their subordinates, and stay abreast of the latest technology in order to purchase necessary equipment.

The duties of computer and information systems managers vary with their specific titles. Chief technology officers, for example, evaluate the newest and most innovative technologies and determine how these can help their organization. The chief technology officer, who often reports to the organization's chief information officer, manages and plans technical standards and tends to the daily information technology issues of their firm. Because of the rapid pace of technological change, chief technology officers must constantly be on the lookout for developments that could benefit their organization. They are responsible for demonstrating to a company how information technology can be used as a competitive weapon that not only cuts costs, but also increases revenue.

Management of information systems (MIS) directors manage information systems and computing resources for entire organizations. They also work under the chief information officer and deal directly with lower-level information technology employees. These managers oversee a variety of user services such as an organization's help desk, which employees can call with questions or problems. MIS directors may also make hardware and software upgrade recommendations based on their experience with an organization's technology (Treven, \& Srica, 1995).

Information system managers need strong communication skills. They coordinate the activities of their unit with those of other units or organizations. They confer with top executives; financial, production, marketing, and other managers; and contractors and equipment and materials suppliers. 


\section{The Increasing Need for Computer and Information Systems Managers}

Employment of computer and information systems managers is expected to increase much faster than the average for all occupations through the year 2010. Technological advancements will increase the employment of computer-related workers; as a result, the demand for managers to direct these workers also will increase. In addition, job openings will result from the need to replace managers who retire or move into other occupations. Opportunities for obtaining a management position will be best for workers possessing an MBA with technology as a core component, advanced technical knowledge, and strong communication and administrative skills (Bureau of Labor Statistics, 2002-03).

Rapid growth in employment can be attributed to the explosion in information technology and the fast-paced expansion of the computer and data processing services industry. In order to remain competitive, companies will continue to install sophisticated computer networks and set up more complex Internet and intranet sites. Keeping a computer network running smoothly is essential to almost every organization. Companies will be more willing to hire managers who can accomplish that (Treven, \& Srica, 1995; Veljovic, 2002).

The security of computer networks will continue to increase in importance as more business is conducted over the Internet. Organizations need to understand how their systems are vulnerable and how to protect their infrastructure and Internet sites from hackers, viruses, and other acts of cyber-terrorism. As a result, there will be a high demand for managers proficient in computer security issues.

Opportunities for those who wish to become computer and information systems managers should be closely related to the growth of the occupations they supervise and the industries in which they are found.

\section{The Requirements for Training and Other Qualifications of Computer and Information Systems Managers}

Strong technical knowledge is essential for computer and information systems managers, who must understand and guide the work of their subordinates, yet also explain the work in nontechnical terms to senior management and potential customers. Therefore, these management positions usually require work experience and formal education similar to that of other computer occupations (Treven, \& Mulej, 2000).

Many computer and information systems managers have experience as systems analysts; others may have experience as computer support specialists, programmers, or other information technology professionals. A bachelor's degree is usually required for management positions, although employers often prefer a graduate degree, especially a master's degree in business administration (MBA) with technology as a core component. This degree differs from a traditional MBA in that there is a heavy emphasis on information technology in addition to the standard business curriculum. This becomes important because more computer and computer and information systems managers make not only important technology decisions but also important business decisions for their organizations. A few computer and computer and information systems managers may have only an associate degree, provided they have sufficient experience and were able to learn additional skills on the job.

Computer and information systems managers need a broad range of skills. In addition to technical skills, employers also seek managers with strong business skills. Employers want managers who 
have experience with the specific software or technology to be used on the job, as well as a background in either consulting or business management. The expansion of electronic commerce has elevated the importance of business insight, because many managers are called upon to make important business decisions. Managers need a keen understanding of people, processes, and customer's needs. Some of the necessary skills for the computer and information systems managers are (Treven, \& Srica, 1995):

- Read and understand work-related materials.

- Motivate, develop, and direct people as they work.

- Identify problems and review information.

- Analyze options and apply solutions.

- Express ideas clearly when speaking or writing.

- Think of original, unusual, or creative ways to solve problems.

- Be aware of others' reactions and understand the possible causes.

- Obtain needed equipment, facilities, and materials and oversee their use.

- Listen to others and ask questions.

- Combine several pieces of information and draw conclusions.

- Manage the time of self and others.

- Determine how a system should work and how changes in operations will affect outcomes.

- Identify what must be changed to reach goals.

- Notice when something is wrong or is likely to go wrong.

- Concentrate and not be distracted while performing a task.

Computer and information systems managers must possess strong interpersonal, communication, and leadership skills because they are required to interact not only with their employees, but also with people inside and outside their organization. They must also possess great team skills to work on group projects and other collaborative efforts. Computer and computer and information systems managers increasingly interact with persons outside their organization, reflecting their emerging role as vital parts of their firm's executive team.

\section{Training of Computer and Information Systems Managers}

In the previous chapter we have already mentioned the knowledge and skills the computer and information systems managers need. They are more successful if their organizations provide appropriate training for them. In this section we shall first answer the question, "What is employee training?" Then we shall turn our attention to the training needs. At last we shall present some methods that can be used within the proces of training. As the number of international organizations increases in today's global environment, we shall also point out the need for cross-cultural training for managers in such organizations. 


\section{What is Employee Training?}

Training is a learning experience in that it seeks a relatively permanent change in an individual that will improve the ability to perform on the job. We typically say training can involve the changing of skills, knowledge, attitudes, or behavior. It may mean changing what employees know, how they work, their attitudes toward work, or their interaction with their coworkers or supervisor (Armstrong, 1996; Boxal, \& Purcell, 2003; Jackson, \& Schuler, 2003).

So why is training so important for both employees and organizations? There are several reasons:

1. Changes in the workplace and the workforce. Both the workplace and the workforce are going through many changes. In terms of the workplace, the increased use of high technology, the continuing shift from a manufacturing to a service economy, and the increasingly global business world necessitates ongoing employee training. In terms of changing workforce, the increasing numbers of immigrants with limited educational background are forcing organizations to provide training often for the purpose of improving basic writing and reading skills (Goldstein, 1989).

2. Maintaining competitiveness and improving productivity. Training is essential for maintaining global competitiveness. Japan and Germany, two of our toughest business competitors, have outstanding training and development programs, which helps them maintain high levels of productivity and flexibility.

3. Regulatory requirements. Various laws require companies to provide training. For example, certain industries, such as the nuclear waste industry, require employees to receive training for a variety of purposes, especially safety-related issues.

In large companies they started to reorganise the training function in order to gain a competitive advantage before others in the market. The new way of organization of this function is related to the strategic goals of the enterprise and is supported by the top managers. Its attribute is to help the organization arrange a work environment which encourages employees to continuously learn. For the organization such a kind of learning is essential. It contributes to making and keeping the organization competitive on the market, in which customer requirements, quality standards, product attributes change permanently, new competitors enter the market, and new technologies which change production processes, are attributes causing no serious trouble to such an organization.

\section{Determining Training Needs}

Training needs are determined by doing an analysis of the organization, the tasks/KSAs, and the employees (Dessler, 2000; Harris, 1997; Jackson, \& Schuler, 2003).

A training needs analysis is a three-step process:

1. An organizational analysis

2. A task/KSA analysis

3. A person analysis.

The purpose of step 1, the organizational analysis, is to examine the organization, unit, or department and determine its basic business strategy, objectives, and goals. In today's constantly changing business environment, the organizational analysis may focus on the company's new business goals and challenges, and the implications for jobs.

The second step, the task and knowledge, skills and abilities (KSAs) analysis, involves obtaining information from the organizational analysis to evaluate the tasks performed in each job and then determine the knowledge, skills, and abilities (KSAs) needed to perform these tasks effectively. 
Need for Training of Computer and Information Systems Managers

The third step, the person analysis, addresses the question of whether certain employees are deficient in the important tasks/KSAs, and whether training would treat the deficiencies. There are several ways to determine employee deficiencies. One of the most popular ways is to examine measures of job performance. For example, any employee who received a less than satisfactory rating on any job dimension might be considered deficient in that area.

\section{Training Methods}

The most popular training methods used by organizations can be classified as either on-the-job or off-the-job training (Dessler, 2000; Treven, \& Mulej, 2000). On-the-job training is provided at the worksite. Off-the-job training is conducted away from the worksite. We begin first with a review of on-the job methods.

There are four basic kinds of on-the-job training:

1. One-on-one instruction.

2. Coaching.

3. Job rotation.

4. Apprenticeship/internship.

In one-on-one instruction, a person who serves as a trainer for the organization meets with the employee at the workplace and instructs the trainee. Generally, the instructional method involves a description of the procedures, along with a visual demonstration by the instructor. Following this, the trainee practices under the supervision of the trainer.

Coaching can be defined as informal, unplanned training and development activities provided by supervisors and peers (Harris, 1997). While coaching may provide valuable help for employees, it should be viewed strictly as a supplement to, rather than a substitute for, formal training program. There are many occasions for which the coaching method is most usefully applied:

- When an employee demonstrates a new skill or ability.

- When an employee express interest in a different job within the organization.

- When an employee seeks feedback.

- When an employee is expressing low morale, violating company policies or practices, or having performance problems.

- When an employee needs help with a new skill following a formal training program.

Job rotation is a formal, planned program that involves assigning trainees to various jobs in different parts of the organization. The purpose of job rotation is to provide trainees with a larger organizational perspective and a greater understanding of different functional areas, as well as a better sence of their own career objectives and interests.

An apprenticeship is a formal program involving a combination of classroom instruction and hands-on practice and training, primarily in the skilled crafts such as carpentry. Although internships are included here with apprenticeships, they are rather different. An internship is a program that provides work experience to students prior to graduation from an academic program. Typically, internships are completed by students in business, law, and the health professions. Therefore, an apprenticeship constitutes a complete program, while an internship is merely one part of a larger educational program. 
Off-the-job training covers a number of techniques - clasroom lectures, films, demonstrations, case studies and other simulation exercises, and programmed instructions. The facilities needed for each of these techniques vary from a small, makeshift clasroom to an elaborate development center with large lecture halls, supplemented by small conference rooms with sophisticated instructional technology equipment. We have summarized the majority of these methods in Table 1.

Table 1: Off-the-job training methods (De Cenzo, \& Robbins, 1996)

\begin{tabular}{ll}
\hline Clasroom lectures & $\begin{array}{l}\text { Lectures designed to communicate specific interpersonal, } \\
\text { technical, or problem-solving skills. }\end{array}$ \\
Videos and Films & $\begin{array}{l}\text { Using various media productions to demonstrate specialized } \\
\text { skills that are not easily presented by other training methods. }\end{array}$ \\
Simulation Exercises & $\begin{array}{l}\text { Training that occurs by actually performing the work. This } \\
\text { may include case analysis, experiential exercises, role playing, } \\
\text { or group decision making. }\end{array}$ \\
Computer Based Training & $\begin{array}{l}\text { Simulating the work environment by programming a computer } \\
\text { to imitate some of the realities of the job. }\end{array}$ \\
Vestibule Training & $\begin{array}{l}\text { Training on actual equipment used on the job, but conducted } \\
\text { away from the actual work setting - a simulated work station. }\end{array}$ \\
Programmed Instruction & $\begin{array}{l}\text { Condensing training materials into highly organized, logical } \\
\text { sequences. May include computer tutorials, interactive video } \\
\text { disks, or virtual reality simulations. }\end{array}$
\end{tabular}

\section{Cross-cultural Training}

Cross-cultural training is important for managers that will carry out their assignments in a foreign country. It prepares them to live and work in a different culture. For the expatriates coping with a new environment is a much greater issue than dealing with a new job.

Cross-cultural training is necessary for expatriate managers and their families before, during and after foreign assignments. It is crucial to remember that when the expetriates arrive, they are foreigners, not the host population. Before the employee and family are relocated to the overseas post, it is necessary to provide much cultural and practical backgraund (Francesco, \& Gold, 1998; Treven, 2002).

Language training is essential for everyone in the family. But cross-cultural training is much more than just language training. It should provide an appreciation of the new culture including details of its history and folklore, economy, politics, religion, social climate, and business practices.

All this training can be carried out through a variety of methods. In Table 2 some of the popular ones are presented together with a brief description of each.

Table 2: Cross-cultural training methods

$\begin{array}{ll}\text { Cultural Briefings } & \begin{array}{l}\text { Explain the major aspects of the host country culture, including } \\ \text { customs, norms, values, traditions. }\end{array} \\ \text { Area Briefings } & \begin{array}{l}\text { Explain the geography, history, economy, law, politics and other } \\ \text { general information about the host country. }\end{array} \\ \text { Role Playing } & \begin{array}{l}\text { Allows the trainee to act out a situation that he or she might face } \\ \text { in living and working in the host country. }\end{array}\end{array}$




\begin{tabular}{ll}
\hline Cases & $\begin{array}{l}\text { Portray a real-life situation in business or personal life to illustrate } \\
\text { some aspect of living or working in the host culture. }\end{array}$ \\
Culture Assimilator & $\begin{array}{l}\text { Provides a written set of situations that the trainee might encoun- } \\
\text { ter in living or working in the host country. }\end{array}$ \\
Field Experiences & $\begin{array}{l}\text { Provide an opportunity for the trainee to go to the host country or } \\
\text { another unfamiliar culture to experience living and working for a } \\
\text { short time. }\end{array}$
\end{tabular}

An organization can choose the most appropriate method for training, applying three situational factors of the expatriate's assignment (Black, \& Mendenhall, 1989):

- culture novelty,

- degree of interaction with host country nationals,

- job novelty.

Culture novelty refers to the difference between the new culture and the expatriate's home culture. The degree of difference can be measured by comparing the cultures by means of models, such as Hofstede's or Hall's, that were discussed in section 2 of our paper.

The degree of interaction with host country nationals refers to how often and at what level the expatriate manager communicates with locals. Last but not least job novelty involves the new job demands, including expectations, job constrains and the degree of autonomy.

\section{Conclusion}

We believe that training alone will not solve the human resource problems experienced in the information technology environment. The solution is associated with maintaining the critical mass of knowledge in each organization. Training will be an essential component in the building of effective corporate strategies (commercial, human resource management, and information technology). But throwing money, time and effort at badly defined objectives will only lead to more trouble.

\section{References}

Armstrong, M. (1996). Personnel management practice. Kogan Page.

Bureau of Labor Statistics, U.S. Department of Labor. (2002-03). Occupational Outlook Handbook, 200203 Edition. Computer and Information Systems Managers.

Black, J.S. \& Mendenhall, M. (1989). A practical but theory-based framework for selecting cross-cultural training methods. Human Resource Management, 28, 511-39.

Boxall P. \& Purcell J. (2003). Strategy and human resource management. Palgrave, Macmillan.

Darlington, G. (1996). Culture: A theoretical review. In P. Joynt \& M. Warner (Eds.), Managing across cultures (pp. 33-55). London: International Thomson Business Press.

De Cenzo, D.A. \& Robbins S.P. (1996). Human resource management. John Wiley \& Sons.

Dessler, G. (2000). Human resource management. Prentice Hall.

Francesco, A. M. \& Gold, B. A. (1998). International organizational behavior. Prentice Hall.

Goldstein, I. (1989). Critical training issues: Past, present and future. In I. Goldstein and Associates, Training and development in organizations. Jossey Bass. 
Harris, M. (1997). Human resource management: A practical approach. Dryden Press.

Hoppe, M.H. (1990). A comparative study of country elites: International differences in work-related values and learning and their implications for management training and development. Unpublished $\mathrm{PhD}$ thesis, University of North Carolina at Chapel Hill.

Jackson S.E. \& Schuler R.S. (2003). Managing human resources, Thomson South-Western.

Treven, S. \& Srica, V. (1995). Informacijski sistemi za managerje. Gospodarski vestnik, Ljubljana.

Treven, S. \& Mulej, M. (2000). Training of employees in information systems department. In S. Hofer \& M. Beneder, $8^{\text {th }}$ Interdisciplinary Information Management Talks (pp. 99-110). Zadov, Tschechien city. IDIMT - 2000 proceedings.

Treven, S. (2002). Training of managers for assignments abroad. In C. Harvie \& B. C. Lee, Sustaining SME innovation, competitiveness and development in the global economy (pp. 712-721). Proceedings. Wollongong.

Veljovic A.V. (2002). Menadžment informacioni sistemi, Kompjuter biblioteka, Cacak.

\section{Biography}

Sonja Treven is Associate Professor at the School of Business and Economics at the University of Maribor in Maribor, Slovenia for the field of information systems, human resource management as well as organisational behaviour.

She defended her doctoral thesis in 1990 at the School of Economics at the University of Zagreb, Croatia. She attended more than 40 Conferences (domestic and international) with her articles in Austria, India, Florida, Australia, Poland, Greece, Croatia and Slovenia. She is the author of 2 books (International Organizational Behavior, 2001; Human Resources Management, 1998) and co-author of 3 books (Information Systems, 1995; Managers and Information Systems, 1994; Strategic Management and Projects, 1991). 